\title{
O QUE É SUSTENTABILIDADE?
}

Antes de iniciarmos o primeiro editorial de 2010, gostaríamos de desejar a todos um ano repleto de realizações e, como quími$\cos$, que este ano seja de novas reações mais eficientes e limpas, novos produtos naturais bioativos, novas teorias e descobertas importantes.

Imaginamos que a maioria dos nossos colegas esteja familiarizada com o termo sustentável. Porém, as notícias divulgadas em jornais, televisão e na internet são confusas e criaram tantas dúvidas sobre o assunto que é bom revisitá-lo. Em muitos Editoriais da Química Nova já foram abordados diversos pontos específicos deste assunto, mas nenhum foi exclusivamente dedicado ao assunto.

A percepção da maioria das pessoas é que a sustentabilidade está relacionada apenas às emissões de gases para a atmosfera como, por exemplo, o gás carbônico, e que este é o único risco a que o planeta está exposto. Isto é um equívoco. Em realidade este é o principal problema, mas não é o único. Foi exatamente esta discussão que ocorreu em meados de dezembro de 2009 em Copenhague (COP-15) que terminou de forma decepcionante, pois os países mais desenvolvidos se eximiram de compromissos pelas emissões de gases durante muitos anos, o que aumentou o efeito estufa, e tentaram jogar muitas das suas responsabilidades para os países em desenvolvimento. Com certeza este será o tema dominante tanto durante este ano como nos próximos.

Em primeiro lugar, é bom esclarecer que desenvolvimento sustentável não se restringe apenas a uma ação, como reduzir as emissões de gases que causam o efeito estufa. Se realizarmos apenas ações no sentido de reduzir as emissões dos gases estufa, tememos que o planeta seja alterado de tal forma que, possivelmente, muitas espécies como as conhecemos agora deixarão de existir.

O termo desenvolvimento sustentável abriga um conjunto de paradigmas para o uso dos recursos que visam atender as necessidades humanas. Este termo foi cunhado em 1987 no Relatório Brundtland da Organização das Nações Unidas que estabeleceu que desenvolvimento sustentável é o desenvolvimento que "satisfaz as necessidades do presente sem comprometer a capacidade das gerações futuras satisfazerem as suas próprias necessidades". Ele deve considerar a sustentabilidade ambiental, econômica e sociopolítica. Dentro da questão ambiental (água, ar, solo, florestas e oceanos), ou seja, tudo que nos cerca precisa de cuidados especiais para que continue existindo. Portanto, as sustentabilidades econômica e sócio-política só têm existência se for mantida a sustentabilidade ambiental.

A conservação do meio ambiente deve ser estar inserida em uma política de desenvolvimento do país, mas é importante enfatizar que ela não pode ser de apenas uma pessoa ou um governo. O meio ambiente deve ser um cuidado de todos com tudo. Os cidadãos devem estar permanentemente alertas para os perigos das ações mais inocentes que são realizadas no meio ambiente. A implementação de ações sustentáveis envolve atos e ações simples como ir a um supermercado, o uso racional de água nas residências, a manipulação adequada do lixo etc., mas deve envolver também atitudes radicais quanto ao consumismo exagerado.

Então, esse tipo de desenvolvimento passa por diversos aspec- tos, porém todos devem convergir para a preservação do meio ambiente. Há pouco mais de 30 anos atrás, defender o meio ambiente era coisa exótica. Muitos até chamavam as pessoas que militavam nesta área de "ecochatos". A militância destes grupos desencadeou a consciência de muitas pessoas e governantes, pois nunca antes se debateu tanto sobre o meio ambiente e a questão da sustentabilidade como nos dias atuais. Porém, mesmo com os alertas dos grupos ambientalistas, a população mundial só começou a tomar consciência do real problema com as graves alterações climáticas que estão ocorrendo e que certamente irão piorar nos próximos anos.

Dentro deste contexto, o que a Química, através de seus cientistas e pesquisadores, pode contribuir para um desenvolvimento sustentável? A resposta é simples, a Química pode trazer o ponto de equilíbrio para este desenvolvimento melhorando os produtos de consumo com novos materiais mais adequados, além de novos métodos de produção de fármacos e produtos químicos intermediários, ambientalmente recomendáveis. Deve-se ressaltar que já há algum tempo a Química vem trabalhando com a concepção de uma ciência ambientalmente mais recomendável, chamada de Química Verde, mas essa ação precisa ser acelerada em face da urgência e do momento político. Devem ser pesquisadas novas reações mais eficientes, visando a diminuição da quantidade de rejeitos gerados e o uso de reagentes mais baratos e menos tóxicos. Porém, a principal necessidade é a substituição dos combustíveis fósseis (recursos não renováveis) e utilização de novas fontes energéticas.

A Química também não pode esquecer do aproveitamento da biomassa renovável terrestre, que é constituída de diversos produtos de baixas e altas massas moleculares como, por exemplo, carboidratos, aminoácidos, lipídios e biopolímeros - como celulose, hemicelulose, quitina, amido, lignina e proteínas. Estas biomassas são utilizadas principalmente na alimentação, mas também devem ser aproveitadas para a produção de combustíveis e produtos químicos. Um exemplo deste tipo de abordagem é o programa Bioen da FAPESP que criou uma rede de pesquisadores voltados para o estudo de novas vias e métodos de obtenção de álcool de segunda geração a partir do bagaço e das folhas da cana-de-açúcar. Somente esta ação pode triplicar a produção do bioetanol sem aumentar a área plantada. Imagine se fosse possível o aproveitamento de $10 \%$ da celulose produzida pelas florestas para a geração de combustíveis e materiais biodegradáveis.

A Sociedade Brasileira de Química e seus Periódicos continuam incentivando os pesquisadores a produzirem trabalhos de alta qualidade que tenham foco na questão do desenvolvimento sustentável. Esta ação pode ser considerada uma contribuição pequena, mas na direção correta. Estamos fazendo a nossa parte neste intrincado dilema entre sustentabilidade e atividade econômica.

Susana I. Córdoba de Torresi

Vera L. Pardini

Vitor F. Ferreira

Editores de QN 


\section{SECRETARIAS REGIONAIS}

\section{Alagoas}

Adriana Santos Ribeiro

Departamento de Química - CCEN - UFAL

Cidade Universitária

57072-970 - Maceió, AL

Fone: (82) 3214-1389 / Fax: (82) 3214-1700

E-mail: aribeiro@qui.ufal.br

\section{Bahia}

Wilson de Araujo Lopes

Departamento de Química Orgânica - UFBA

Campus Universitário de Ondina

40170-290 - Salvador, BA

Fone: (71) 3237-5784 Ramal: 238

E-mail: willopes@ufba.br

\section{Campinas}

Claudia Longo

Instituto de Química - UNICAMP

Caixa Postal 6154

13084-971 - Campinas, SP

Fone: (19) 3521-3029 / fax: (19) 3521-3023

E-mail: clalongo@iqm.unicamp.br

\section{Ceará}

Otília Deusdênia Loiola Pessoa

Departamento de Química Orgânica e Inorgânica, Centro de Ciências - UFC

Caixa Postal 12.200

60455-760 - Fortaleza, CE

Fone: (85) 3288-9441

E-mail: opessoa@ufc.br

\section{Distrito Federal}

Alexandre Gustavo Soares do Prado

Instituto de Química - UnB

79970-900 - Brasília, DF

Fone: (61) 3307-2156

E-mail: agsprado@unb.br

\section{Goiás}

Liliane Magalhães Nunes

Inst. De Química - UFG

CP 131

74001-970 - Goiânia, GO

Fone: (62) 521 - 1059

E-mail: liliane@quimica.ufg.br

Interior Paulista Waldemar Saffioti

Dulce Helena Siqueira Silva

Instituto de Química - UNESP

Av. Prof. Francisco Degni, s/n

Caixa Postal 355

1480-1970 - Araraquara, SP

Fone: (16) 3301-6658 / Fax: (16) 3301-6659

E-mail: dhsilva@iq.unesp.br

\section{ALIMENTOS E BEBIDAS (BA)}

Diretor: Douglas Wagner Franco (IQSC-USP)

douglas@iqsc.usp.br

\section{CATÁLISE (CT)}

Simoni M. Plentz Meneghetti (UFAL)

simoni.plentz@terra.com.br

QUÍMICA DE MATERIAIS (QM)

Aldo Jose Gorgatti Zarbin (UFPR)

aldo@quimica.ufpr.br

ENSINO DE QUÍMICA (ED)

Daisy de Brito Rezende

dbrezend@iq.usp.br

QUÍMICA AMBIENTAL (AB)

Perola de Castro Vasconcellos (IQ-USP)

perola@iq.usp.br

\section{Maranhão}

Isaide de Araujo Rodrigues

Departamento de Química - UFMA

Av. dos Portugueses, s/n

Campus do Baçanga

65080-040 - São Luiz, MA

Fone: (98) 2109-8228 Ramal 8879

E-mail: isaide@ufma.br

Minas Gerais

Ruth Helena Ungaretti Borges

Departamento de Química - ICEx - UFMG

Campus Universitário Pampulha

31270-901 - Belo Horizonte, MG

Fone: (31) 3409-5774

E-mail: ruborges@netuno.lcc.ufmg.br

Paraíba

Mário Luiz A. de A. Vasconcelos

Depto. de Química - CCEN - UFPB

58059-900 - João Pessoa, PB

Fone: 83 3216-7413

E-mail:mlaav@quimica.ufpb.br

\section{Paraná}

Neide Hiroko Takata

DIRCOAV - UNICENTRO

85015-430 - Gurapuava, PR

Fone: (42) 3621-1084

E-mail:neide@unicentro.br

Pernambuco

Severino Alves Junior

Departamento de Química - CCEN - UFPE

Av. Luiz Freire. s/n

50740-540 - Recife, PE

Fone: (81) 3271-8442

E-mail: salvesjr@ufpe.br

Piauí

Welter Cantânhede da Silva

Depto. de Química da UFPI

Campus Ininga Ministro Petrônio Portela

64049-550 - Teresina, PI

Fone: (86) 3215-5840

E-mail: welter@ufpi.br

Rio de Janeiro

Carlos Alberto Manssour Fraga

LASSBio-Fac. de Farmácia

C. Postal 68023

21944-971 - Rio de Janeiro, RJ

Fone: (21) 2260-9192 Ramal 253

E-mail: cmfraga@pharma.ufrj.br

\section{DIVISÕES SBQ / DIRETORES}

ELETROQUÍMICA E ELETROANALÍTICA (EQ) Artur de Jesus Motheo (IQSC-USP) artur@iqsc.usp.br

\section{FÍSICO-QUÍMICA (FQ)}

Edvaldo Sabadini (IQ-UNICAMP)

\section{FOTOQUÍMICA (FT)}

Mauricio da Silva Baptista (IQ-USP)

baptista@iq.usp.br

\section{QUÍMICA MEDICINAL (MD)}

Adriano Defini Andricopulo (IFSC/USP)

aandrico@if.sc.usp.br sabadini@iqm.unicamp.br
Rio Grande do Norte

Tereza Neuma de C. Dantas

Departamento de Química - CCE

Campus Universitário

C. Postal 1662

59072-970 - Natal, RN

Fone: (84) 3215-3827

E-mail: tereza@eq.ufrn.br

Rio Grande do Sul

Sibele Berenice Castella Pergher Departamento de Química - URI

Av. Sete de Setembro, 1621

Campus Erechim

99700-000 - Erechim, RS

Fone: (54) 3520-9000 Ramal 9133

E-mail: pergher@uricer.edu.br

\section{Roraima}

Luiz Antônio Mendonça Alves da Costa

Departamento de Química - UFRR

Av. Eng. Garcez, 2413 - B1. III

69304-000 - Boa Vista, RR

Fone: (95) 3621-3140

E-mail: luizufrr@gmail.com

\section{Santa Catarina}

Edson Minatti

Departamento de Química - UFSC

Campus Universitário

88010-970 - Florianópolis, SC

Fone: (48) 33316844

E-mail: minatti@pq.cnpq.br

\section{Sergipe}

Carlos Alexandre Borges Garcia

Departamento de Química - CCET

Lab. de Química Analítica Ambiental

49100-000 - São Cristovão, SE

Fone: (79) 2105-6649

E-mail: cgarcia@ufs.br

Viçosa

Cláudio Ferreira Lima

Departamento de Química - CCE - UFV

Av. P.H. Rolfs s/n

36571-000 - Viçosa, MG

Fone: (31) 3899-3053

E-mail: cflima@ufv.br

PRODUTOS NATURAIS (PN)

Maria da Conceição F. de Oliveira (UFC) mcfo@ufc.br

\section{QUÍMICA INORGÂNICA (QI)}

Stela Maris Romanowski

stela@química.ufpr.br

\section{QUÍMICA ANALÍTICA (QA)}

Fábio Rodrigo Piovezani Rocha (IQ-USP)

frprocha@iq.usp.br

QUÍMICA ORGÂNICA (QO)

Silvio do Desterro Cunha (UFBA)

silviodc@ufba.br 